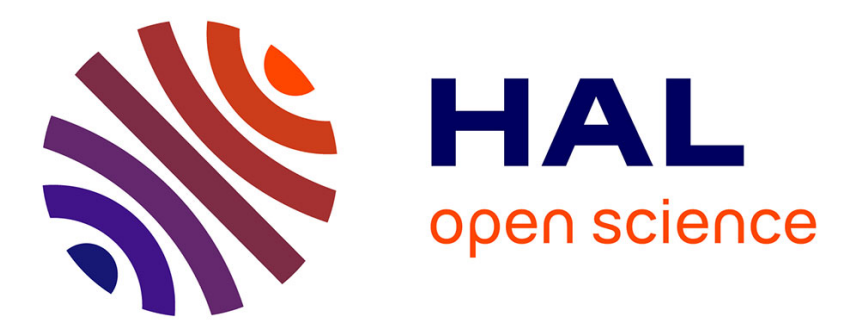

\title{
Discordant biological parameters of remission in acromegaly do not increase the risk of hypertension or diabetes: a study with the Liege Acromegaly Survey database
}

\author{
Vincent Amodru, P. Petrossians, A. Colao, B. Delemer, L. Maione, \\ S.J.C.M.M. Neggers, B. Decoudier, P. Kamenicky, Frederic Castinetti, V. \\ Hana, et al.
}

\section{- To cite this version:}

Vincent Amodru, P. Petrossians, A. Colao, B. Delemer, L. Maione, et al.. Discordant biological parameters of remission in acromegaly do not increase the risk of hypertension or diabetes: a study with the Liege Acromegaly Survey database. Endocrine, 2020, 70 (1), pp.134-142. 10.1007/s12020020-02387-1 . hal-03223227

\section{HAL Id: hal-03223227 \\ https://hal-amu.archives-ouvertes.fr/hal-03223227}

Submitted on 12 May 2021

HAL is a multi-disciplinary open access archive for the deposit and dissemination of scientific research documents, whether they are published or not. The documents may come from teaching and research institutions in France or abroad, or from public or private research centers.
L'archive ouverte pluridisciplinaire HAL, est destinée au dépôt et à la diffusion de documents scientifiques de niveau recherche, publiés ou non, émanant des établissements d'enseignement et de recherche français ou étrangers, des laboratoires publics ou privés. 


\title{
Discordant biological parameters of remission in acromegaly do not increase the risk of hypertension or diabetes: a study with the Liege Acromegaly Survey database
}

\author{
V. Amodru ${ }^{1}$ - P. Petrossians ${ }^{2} \cdot$ A. Colao $^{3} \cdot$ B. Delemer ${ }^{4} \cdot$ L. Maione ${ }^{5}$ - S.J.C.M.M. Neggers ${ }^{6} \cdot$ B. Decoudier $^{4}$. \\ P. Kamenicky ${ }^{5}$ F. Castinetti ${ }^{1} \cdot$ V. Hana ${ }^{7} \cdot$ R. Pivonello ${ }^{3} \cdot$ D. Carvalho ${ }^{8} \cdot$ T. Brue $^{1} \cdot$ A. Beckers ${ }^{2} \cdot$ P. Chanson $^{5} \cdot$ T. Cuny $^{1}$
}

\begin{abstract}
Purpose Acromegaly is a rare disease due to growth hormone (GH)-secreting pituitary adenoma. GH and IGF-1 levels are usually congruent, indicating either remission or active disease; however, a discrepancy between GH and IGF-1 may occur. We aimed to evaluate the outcome of diabetes mellitus (DM) and hypertension (HT) in acromegalic patients with congruent GH and/or IGF-1 levels vs. discordant biochemical parameters.

Methods Retrospective analysis of the data of 3173 patients from the Liege Acromegaly Survey (LAS) allowed us to include 190 patients from 8 tertiary referral centers across Europe, treated by surgery, with available data concerning DM and HT both at diagnosis and at the last follow-up (LFU). We recorded the number of anti-HT and anti-DM drugs used at the first evaluation and at LFU for every patient.

Results Ninety-nine patients belonged to the REM group (concordant parameters), 65 patients were considered as $\mathrm{GH}_{\mathrm{dis}}$ (high random GH/controlled IGF-1), and 26 patients were considered as IGF-1 $1_{\text {dis }}$ (high IGF-1/controlled random GH). At diagnosis, 72 patients $(37.8 \%)$ had HT and 54 patients had DM (28.4\%). There was no statistically significant difference in terms of the number of anti-HT and anti-DM drugs at diagnosis versus LFU (mean duration: $7.3 \pm 4.5$ years) between all three groups.

Conclusion The long-term outcome of DM and HT in acromegaly does not tend to be more severe in patients with biochemical discordance in comparison with patients considered as in remission on the basis of concordant biological parameters, suggesting that patients with biochemical discordance do not require a closer follow-up.
\end{abstract}

Keywords Acromegaly $\cdot \mathrm{GH} \cdot \mathrm{IGF}-1 \cdot$ Discordance $\cdot$ Hypertension $\cdot$ Diabetes

\section{Introduction}

Acromegaly is a rare disease generally due to a growth hormone $(\mathrm{GH})$-secreting pituitary adenoma [1]. Because the

T. Cuny

thomas.cuny@ap-hm.fr

1 Aix Marseille Univ, APHM, INSERM, MMG, Service d'endocrinologie, Hôpital de la Conception, Marseille, France

2 Department of Endocrinology, CHU de Liège, Université de Liege, Liège, Belgium

3 Dipartimento Di Medicina Clinica e Chirurgia, Sezione di Endocrinologia, University "Federico II", Naples, Italy

4 Service d'endocrinologie, CHU de Reims, Reims, France diagnosis is usually delayed by 5-10 years, the occurrence, progression, and aggravation of comorbidities related to the excess of GH are likely to occur [2].

Service d'Endocrinologie et des Maladies de la Reproduction, Hôpital de Bicêtre, Le Kremlin-Bicêtre, France

6 Section of Endocrinology Department of Medicine, Erasmus University Medical Center, Rotterdam, The Netherlands

7 Third Department of Internal Medicine, 1st Faculty of Medicine, Charles University, Prague, Czech Republic

8 Department of Endocrinology Diabetes and Metabolism, Centro Hospitalar Universitário S. João, Faculty of Medicine, Instituto de Investigação e Inovação em Saúde, Universidade do Porto, Porto, Portugal 
Hypertension (HT) is a major contributor to cardiovascular mortality in acromegaly and is reported to affect approximately one-third of patients [3]. In some series, it has even been reported to be found in up to $60 \%$ of acromegalic patients [2]. HT probably results from concomitant factors leading to expansion of extracellular fluid volume: an antinatriuretic effect of the GH/IGF-1 axis [4], an increase of the peripheral vascular resistance, and a development of sleep apnea syndrome [5]. Likewise, the prevalence of impaired glucose tolerance and diabetes mellitus (DM) in acromegaly have been reported to range from 19 to $56 \%$ depending on the study [2, 6]. In that setting, DM is usually associated with insulin-resistance and hypertriglyceridemia [7]. This metabolic profile, together with HT, induces an increased overall risk of cardiovascular morbidities and mortality in acromegalic patients [8]. Both the screening and management of these complications are essential during the initial evaluation and the follow-up of acromegalic patients, as recommended by the current guidelines [3, 9]. Recent data provided by the analysis of the French acromegaly registry showed an improvement in the biochemical control of the disease over the past decades with a significant decrease in the incidence of acromegaly induced comorbidities [10]. Currently, criteria used to define biochemical control remains a matter of debate. Certain expert consensus, based on the use of ultrasensitive GH assays, recommend defining biochemical remission of the disease, a normalization of IGF-1 for age and sex and a GH nadir below $0.4 \mu \mathrm{g} / \mathrm{L}$ after $75 \mathrm{~g}$ Oral Glucose Tolerance Test (OGTT) in patients with no glucose disorder [11]. However, it remains uncertain if this low cutoff (as compared with a cutoff of $1 \mu \mathrm{g} / \mathrm{L}$ ) really does improve metabolic outcomes [12], nor markedly influences the proportion of patients who achieve biochemical remission [11]. The Endocrine Society suggests to achieve, as a therapeutic goal, a random $\mathrm{GH}<1 \mu \mathrm{g} / \mathrm{L}$ together with a normalized IGF-1 [9]. Currently, there are several lines of evidence which support that control of both parameters, namely GH and IGF-1, is required to avoid the onset of metabolic complications $[13,14]$. In most cases, respective levels of GH and IGF-1 are congruent, indicating either remission or active disease, however, it has been reported that in up to $25 \%$ of surgically treated patients with acromegaly, naïve to somatostatin analogs (SSAs) or radiation, a discrepancy between GH and IGF-1 may occur [15].

In this retrospective study, our aim was therefore to evaluate the outcome of acromegaly induced comorbidities (HT and DM) in patients with biochemical remission based on concordant biochemical parameters and in those with discordant GH and/or IGF-1 levels.

\section{Material and methods}

\section{Study design and subjects}

We retrospectively analyzed the data of 3173 patients with an established diagnosis of acromegaly from the Liege Acromegaly Survey (LAS) database $[16,17]$. Among them, a total of 190 patients were eligible for this study because they were only treated by surgery, without any other medical treatment (before and/or after surgery) and/or radiotherapy. Moreover, patients did not present with any conditions known to interfere with the GH/IGF-1 axis (see exclusion criteria below). Their data concerning DM and HT were available both at diagnosis and at last follow-up (LFU). Patients have been diagnosed and followed in eight European tertiary referral centers, in France (Hôpital de la Conception, Marseille $[n=31$ patients]; Paris Sud University, Le Kremlin-Bicêtre $[n=50]$; Centre Hospitalier Universitaire de Reims [ $n=23]$ ), Belgium (Centre Hospitalier Universitaire de Liège $[n=27]$ ), Italy (Federico II University, Naples $[n=31]$ ), Portugal (Centro Hospitalar Universitário S. João, Porto $[n=17]$ ), Spain (Hospital Universitario de la Ribera, Valencia $[n=3])$, the Netherlands (Erasmus University Medical Center, Rotterdam $[n=$ 5]) and eventually Czech Republic (Charles University, Prague $[n=3]$ ). Patients were only eligible for this study if they fulfilled the following criteria:

(1) Pituitary adenoma operated by TSS only, with positivity for GH immunostaining on the histopathological analysis.

(2) Considered in biochemical remission or presenting with mild discordant GH or IGF-1 levels as defined in the next paragraph.

(3) Biochemical evaluation of somatotroph axis (IGF-1 and random $\mathrm{GH}$ ) after surgery (thereafter mentioned as $\mathrm{T} 1$ ) and at LFU without confounding factors for GH and/or IGF-1 interpretation (see below).

(4) A similar biochemical status between $\mathrm{T} 1$ and the LFU. Patients who changed their status (e.g., GH discordant to remission) exempted from the analysis.

(5) Pituitary MRI evaluation at diagnosis and LFU (to confirm the absence of a residual pituitary adenoma).

Exclusion criteria included patients without a proper initial evaluation of their comorbidities, patients uncured by surgery (increased IGF-1 levels and random GH $\geq 1 \mu \mathrm{g} / \mathrm{L}$ ) and/or under medical treatments (SSAs, cabergoline or pegvisomant) or radiation therapy, and eventually, patients with confounding factors for GH and/or IGF-1 interpretation (pregnancy, puberty, estrogen therapy, renal insufficiency, liver failure, and hypothyroidism). 


\section{Biochemical evaluation}

Postsurgical criteria of remission were defined according to the current guidelines with normal IGF-1 levels for age and sex and random $\mathrm{GH}<1 \mu \mathrm{g} / \mathrm{L}[9,11]$. GH discordance was defined as random $\mathrm{GH} \geq 1 \mu \mathrm{g} / \mathrm{L}$ with normal IGF-1 levels for age and sex. IGF-1 discordance was defined by abnormal elevated IGF-1 levels with a random $\mathrm{GH}<1 \mu \mathrm{g} / \mathrm{L}$. According to the biochemical status of each patient, we compared the outcome of comorbidities in three different populations: patients in biochemical remission (REM), GH discordant patients $\left(\mathrm{GH}_{\mathrm{dis}}\right)$, and IGF-1 discordant patients $\left(\right.$ IGF- $\left.1_{\text {dis }}\right)$. Notably, we did not consider GH under OGTT (=nadir GH) to categorize these subgroups of patients as this data was inconstantly performed in the different aforementioned centers and because a previous study suggested a low rate of discordance by using $1 \mu \mathrm{g} / \mathrm{L}$ as a cutoff level for "safe" GH [18].

GH and IGF-1 were assessed using different kits in the different centers; however, a rigorous evaluation for each patient was completed, the same kit was used at $\mathrm{T} 1$ and during follow-up. Overall, two different kits were used for GH measurement amongst the different centers, namely the IDS-iSYS Human GH kit (immunodiagnostic system ${ }^{\circledR}$, REF -3700 ) and the LIAISON ${ }^{\circledR}$ hGH assay $\left(\right.$ DiaSorin $^{\circledR}$ ). For IGF1, a total of three different kits were used: IDS-iSYS IGF-1 (immunodiagnostic system ${ }^{\circledR}$ REF IS-3900/IS-3930), LIAISON $^{\circledR}$ IGF-1 assay (DiaSorin ${ }^{\circledR}$ ) and for some patients, IGF-1 have been determined by the Nichols Advantage IGF-I assay (Nichols Institute Diagnostics, San Juan Capistrano, CA).

\section{Outcome of comorbidities}

In every group of patients, we assessed the existence of DM and HT at diagnosis and LFU. DM was defined by two fasting plasma glucose level $\geq 126 \mathrm{mg} / \mathrm{dl}(7.0 \mathrm{mmol} / \mathrm{L})$ or a 2-h plasma glucose $\geq 200 \mathrm{mg} / \mathrm{dl}(11.1 \mathrm{mmol} / \mathrm{L})$ during OGTT or $\mathrm{HbA} 1 \mathrm{c} \geq 6.5 \%(48 \mathrm{mmol} / \mathrm{mol})$ and arterial HT by systolic or diastolic blood pressure $\geq 130 / 80 \mathrm{mmHg}$. Prediabetes was defined by a fasting plasma glucose level between 100 and $125 \mathrm{mg} / \mathrm{dl}(5.6-6.9 \mathrm{mmol} / \mathrm{L})$ or a 2 -h plasma glucose between 140 and $199 \mathrm{mg} / \mathrm{dl}(7.8-11.0 \mathrm{mmol} / \mathrm{L})$ or $\mathrm{HbAlC}$ between 5.7 and $6.4 \%$ (39-46 mmol/mol). In order to assess the severity of each comorbidity, we recorded the number of antihypertensive drugs $(0,1,2,3,4$, and $>4)$ and antidiabetic drugs used $(0,1,2,3$, Insulin) at the first evaluation and at the LFU for each patient.

\section{Statistical analysis}

For statistical analysis, GraphPad Prism $^{\circledR}$ version 6.04 (Graph-Pad Software, San Diego, CA, USA) was used. Continuous data is presented as mean $\pm \mathrm{SD}$, while categorical variables are presented as absolute/relative frequencies. We performed statistical comparisons of quantitative data with the nonparametric Mann-Whitney-Wilcoxon test or ANOVA (Kruskal Wallis test). For statistical comparisons of dichotomous data, we used the $\chi^{2}$ test. All statistical tests were two sided with $p$ values of $<0.05$ considered significant.

\section{Results}

\section{Patient characteristics}

One hundred and ninety patients were included in this multicenter, retrospective study. Ninety-nine patients belonged to the REM group, 65 were $\mathrm{GH}_{\text {dis }}$, and 26 were IGF- $1_{\text {dis }}$. Mean age at diagnosis was comparable between the three groups (Table 1). The mean durations of follow-up (i.e., time between surgery and the LFU) were $6.2 \pm 3.5$, $8.2 \pm 5.4$ and $9.3 \pm 5.1$ years in the REM, $\mathrm{GH}_{\mathrm{dis}}$, and IGF$1_{\text {dis }}$ group, respectively. First biochemical evaluation after surgery was performed at $3.6 \pm 1.2,4.1 \pm 1$, and $3.8 \pm$ 1.2 months, respectively. According to inclusion criteria, mean values of GH and random IGF-1 did not differ significantly between T1 and the LFU in every specific subgroups (Fig. 1a, b). In the whole cohort of patients, the mean maximum tumor diameter at diagnosis was $15.7 \pm$ $6.6 \mathrm{~mm}$ and it did not differ significantly between the different groups. Importantly, there was not a higher proportion of invasive tumors on the MRI in the $\mathrm{GH}_{\mathrm{dis}}$ group, as compared with the two other groups of patients. Data regarding Body Mass Index (BMI) at diagnosis and LFU were available in 84 patients from the REM group, 56 patients from the $\mathrm{GH}_{\mathrm{dis}}$ group and 19 patients in the IGF- $1_{\text {dis }}$ group. In the REM group, the mean value of random $\mathrm{GH}$ was $0.41 \pm 0.26 \mu \mathrm{g} / \mathrm{L}$ at the LFU. Mean value of IGF-1 in this group was $0.61 \pm 0.1$ upper limit of normal (ULN). Finally, the mean BMI in the REM group was $26.9 \pm 3.9 \mathrm{~kg} /$ $\mathrm{m}^{2}$ at diagnosis and $28.2 \pm 4.8 \mathrm{~kg} / \mathrm{m}^{2}$ at the LFU, respectively $(n=84, p<0.01)$.

In the $\mathrm{GH}_{\mathrm{dis}}$ group, mean IGF-1 was $0.7 \pm 0.2 \mathrm{ULN}$ with a mean random $\mathrm{GH}$ of $2.77 \pm 1.83 \mu \mathrm{g} / \mathrm{L}$ at LFU. Mean BMI were $25.4 \pm 4.3 \mathrm{~kg} / \mathrm{m}^{2}$ at diagnosis and $26.3 \pm 4.7 \mathrm{~kg} / \mathrm{m}^{2}$ at the LFU, respectively $(p=0.03)$.

In the IGF- $1_{\text {dis }}$ group, the mean value of IGF- 1 was $1.3 \pm$ $0.3 \mathrm{ULN}$, and the mean value of random GH was $0.39 \pm$ $0.21 \mu \mathrm{g} / \mathrm{L}$ at the LFU. Mean BMI was $30.3 \pm 5.6 \mathrm{~kg} / \mathrm{m}^{2}$ at diagnosis and $30.7 \pm 6 \mathrm{~kg} / \mathrm{m}^{2}$ at $\mathrm{LFU}(n=19$, NS). An overview of patient characteristics is represented in Table 1 and the difference in mean BMI between diagnosis and last follow for every subgroup of patients is presented in Fig. 2.

The mean random $\mathrm{GH}$ at the LFU was significantly higher in the $\mathrm{GH}_{\mathrm{dis}}$ group as compared with the REM group $(2.77 \pm 1.83 \mu \mathrm{g} / \mathrm{L}$ vs. $0.41 \pm 0.26 \mu \mathrm{g} / \mathrm{L}$, respectively, 
Table 1 Clinical and paraclinical features of the studied population

\begin{tabular}{|c|c|c|c|c|c|c|c|}
\hline & $\begin{array}{l}\text { Total } \\
(n=190)\end{array}$ & $\begin{array}{l}\text { REM } \\
(n=99)\end{array}$ & $\begin{array}{l}\mathrm{GH}_{\mathrm{dis}} \\
(n=65)\end{array}$ & $\begin{array}{l}\text { IGF- } 1_{\text {dis }} \\
(n=26)\end{array}$ & $p$ value $^{\mathrm{a}}$ & $p$ value $\mathrm{e}^{\mathrm{b}}$ & $p$ value $^{\mathrm{c}}$ \\
\hline \multicolumn{8}{|l|}{ General features } \\
\hline Female, $n(\%)$ & $106(55.7)$ & $55(55.5)$ & $42(64.6)$ & $9(34.6)$ & 0.90 & 0.22 & 0.06 \\
\hline Age at diagnosis, mean $\pm \mathrm{SD}$ & $47.0 \pm 9.6$ & $47.1 \pm 8.9$ & $46.9 \pm 9.4$ & $46.9 \pm 8.7$ & 0.78 & 0.91 & 0.96 \\
\hline Follow-up (years), mean $\pm \mathrm{SD}$ & $7.3 \pm 4.5$ & $6.2 \pm 3.5$ & $8.2 \pm 5.4$ & $9.3 \pm 5.1$ & 0.44 & 0.19 & 0.35 \\
\hline \multicolumn{8}{|l|}{ Clinical features at diagnosis } \\
\hline Hypertension, $n(\%)$ & $72(37.8)$ & $39(39.3)$ & $25(38.5)$ & $8(30.7)$ & 0.61 & 0.90 & 0.41 \\
\hline Diabetes mellitus, $n(\%)$ & $54(28.4)$ & $27(27.3)$ & $19(29.2)$ & $8(30.7)$ & 0.74 & 0.78 & 0.72 \\
\hline Glucose intolerance, $n(\%)$ & $16(8.4)$ & $7(7.1)$ & $4(6.1)$ & $5(19.2)$ & 0.48 & 1 & 0.12 \\
\hline \multicolumn{8}{|l|}{ Imaging features at diagnosis } \\
\hline Macroadenoma, $n(\%)$ & $129(67.8)$ & $66(66.6)$ & $43(66.1)$ & $20(76.9)$ & 0.70 & 0.94 & 0.31 \\
\hline Size $(\mathrm{mm})$, mean $\pm \mathrm{SD}$ & $15.7 \pm 6.6$ & $14.8 \pm 7.3$ & $14.9 \pm 7.1$ & $15.8 \pm 3.5$ & 0.21 & 0.31 & 0.39 \\
\hline Invasion, $n(\%)$ & $39(20.5)$ & $17(17.2)$ & $14(21.5)$ & $8(30.7)$ & 0.23 & 0.48 & 0.12 \\
\hline \multicolumn{8}{|l|}{ Biological features at last follow-up } \\
\hline Random GH $(\mu \mathrm{g} / \mathrm{L})$, mean \pm SD & $1.24 \pm 1.12$ & $0.41 \pm 0.26$ & $2.77 \pm 1.83$ & $0.39 \pm 0.21$ & $1.5 \times 10^{-9}$ & $2 \times 10^{-8}$ & 0.37 \\
\hline IGF-1 $(\%$ ULN $)$, mean \pm SD & $0.74 \pm 0.23$ & $0.61 \pm 0.16$ & $0.69 \pm 0.16$ & $1.29 \pm 0.29$ & $2 \times 10^{-7}$ & 0.82 & $4 \times 10^{-9}$ \\
\hline
\end{tabular}

${ }^{\mathrm{a}} \mathrm{GH}$ and IGF-1 discord vs. in remission

${ }^{\mathrm{b}} \mathrm{GH}$ discord vs. in remission

${ }^{c}$ IGF-1 discord vs. in remission

A

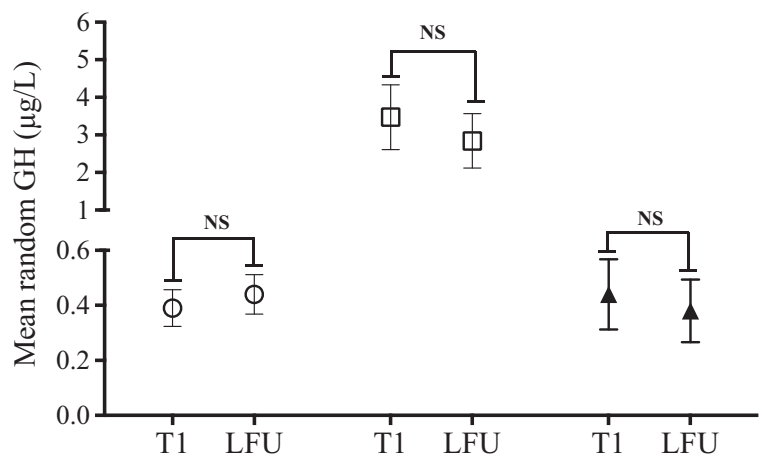

B

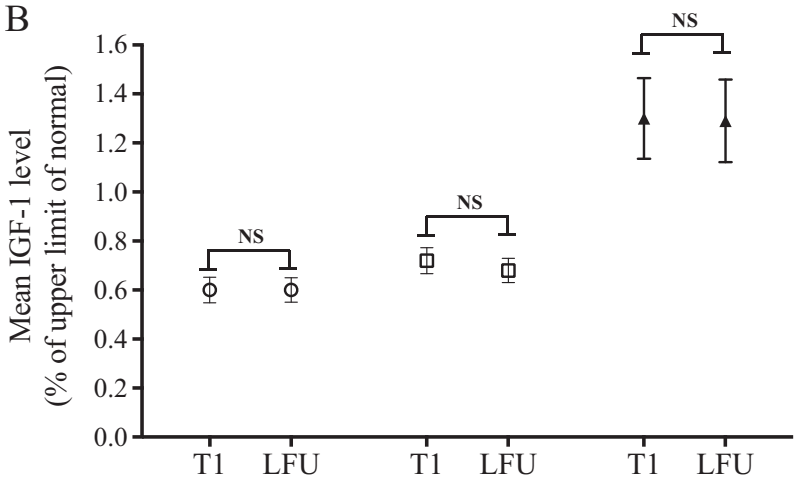

Fig. 1 Mean values of random GH (a) and IGF-1, as expressed by \% of ULN (b), in the three different subgroups of patients (REM: open circles, $\mathrm{GH}_{\mathrm{dis}}$ : open squares and IGF- $1_{\text {dis }}$ : triangles) at $\mathrm{T} 1$ and Last Follow-Up (LFU). Results are represented as means with 95\% confidence interval. NS no significant

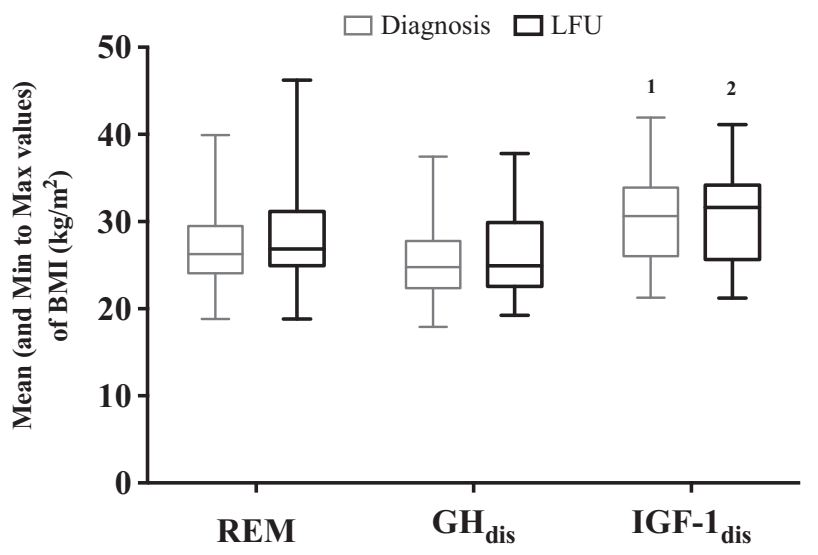

Fig. 2 Values of BMI in the REM, $\mathrm{GH}_{\mathrm{dis}}$ and $\mathrm{IGF}-1_{\text {dis }}$ groups at diagnosis and LFU (LFU). Results are expressed as mean $\pm \mathrm{min} / \mathrm{max}$ values of BMI. 1: $p<0.05$ vs. REM diagnosis and $p<0.005$ vs. $\mathrm{GH}_{\mathrm{dis}}$ diagnosis 2: $p<0.01$ vs. $\mathrm{GH}_{\text {dis }} \mathrm{LFU}$

$p<0.001)$. Accordingly, mean value of IGF-1 was higher in the IGF- $1_{\text {dis }}$ group as compared with the REM group $(1.3 \pm$ $0.3 \mathrm{ULN}$ vs $0.74 \pm 0.23 \mathrm{ULN}$, respectively, $p<0.001$ ).

\section{Impact of GH/IGF-1 discordance on the evolution of hypertension and diabetes mellitus}

According to our definition criteria, a total of 72 patients $(37.8 \%)$ had HT at diagnosis (REM group [ $n=39], \mathrm{GH}_{\mathrm{dis}}$ group $[n=25]$ and IGF- $1_{\text {dis }}$ group $[n=8]$, Table 1) and 63 patients $(33.1 \%)$ at the LFU (REM group $[n=35], \mathrm{GH}_{\mathrm{dis}}$ 
group $[n=21]$ and IGF- $1_{\text {dis }}$ group $\left.[n=7]\right)$. The same number of patients $(n=54,28.4 \%)$ were diagnosed with $\mathrm{DM}$ at diagnosis (REM group [ $n=27], \mathrm{GH}_{\mathrm{dis}}$ group [ $n=$ $19]$, and IGF- $1_{\text {dis }}[n=8]$ ) and at the LFU (REM group [ $n=$ 29 ], $\mathrm{GH}_{\text {dis }}$ group $[n=18]$, and IGF- $\left.1_{\text {dis }}[n=7]\right)$.

Only ten patients $(5.2 \%$ of the whole cohort) had a prediabetic state at $\mathrm{T} 1$ and the LFU. They belonged to the groups as follows: $\operatorname{REM}(n=5), \mathrm{GH}_{\mathrm{dis}}(n=2)$, and IGF- $1_{\mathrm{dis}}$ $(n=3)$. Among these ten prediabetic patients, five had HT at T1 (mean number of anti-HT drugs, $0.4 \pm 0.5$ ), and six at the LFU (mean number of anti-HT drugs, $0.2 \pm 0.3$ ).

HbA1C was available in diabetic patients only $(n=54)$, and its mean value was $7.4 \pm 1.8 \%$ at $\mathrm{T} 1$ versus $6.4 \pm 0.8 \%$ at the LFU, irrespective of the GH/IGF-1 subgroup ( $p=$ 0.06). Mean value of HbAlc did not differ significantly between $\mathrm{T} 1$ and the LFU in the REM, $\mathrm{GH}_{\mathrm{dis}}$ and IGF- $1_{\text {dis }}$ group, respectively (data not shown). Likewise, the mean HbA1c at LFU between diabetic patients of the REM (6.6 \pm $0.8 \%)$ the $\mathrm{GH}_{\mathrm{dis}}(6.5 \pm 0.9 \%)$ or the IGF- $1_{\text {dis }}(6.1 \pm 0.6)$ group, did not differ significantly (data not shown).

The mean number of anti-HT drugs used at diagnosis was similar between the different groups $(0.43 \pm 0.7,0.64 \pm$ 1 and $0.42 \pm 0.8$ in the REM, the $\mathrm{GH}_{\text {dis }}$ and the IGF- $1_{\text {dis }}$ group, respectively, $p=0.27$, Table 2). Furthermore, the mean number of anti-HT drugs used remained the same in the three different groups at diagnosis and at the LFU (Table 2 ). We only observed in the IGF- $1_{\text {dis }}$ group that the number of patients treated with 1 anti-HT drug increased from 1 to 5 between diagnosis and LFU, and those treated with 2 anti-HT drugs decreased from 5 to 1 . However, the difference was not statistically significant.

Concerning DM, the mean number of antidiabetic drugs recorded in the REM, the $\mathrm{GH}_{\mathrm{dis}}$ and the IGF- $1_{\text {dis }}$ groups, respectively, did not differ significantly at diagnosis $(p=$ 0.68 , Table 3$)$ as well as at the LFU ( $p=0.18$, Table 3$)$.

\section{Discussion}

Disease control represents the main goal in acromegalic patients, as it is strongly correlated with a better outcome in terms of both overall survival and prevention of comorbidities[19, 20]. Discrepancy between GH and IGF-1, the two biochemical parameters used in the follow-up of acromegaly, is not a rare event, as it occurs in up to $25 \%$ of patients. This situation can easily be the source of misunderstanding for the clinician and anxiety for the patient, and eventually, can wrongly question the efficacy of the therapeutic regimen [21].

In this study, we assessed the impact of GH/IGF-1 discrepancy on the occurrence and severity of two metabolic comorbidities of acromegaly, namely arterial HT and DM. We made sure to include patients who were surgically

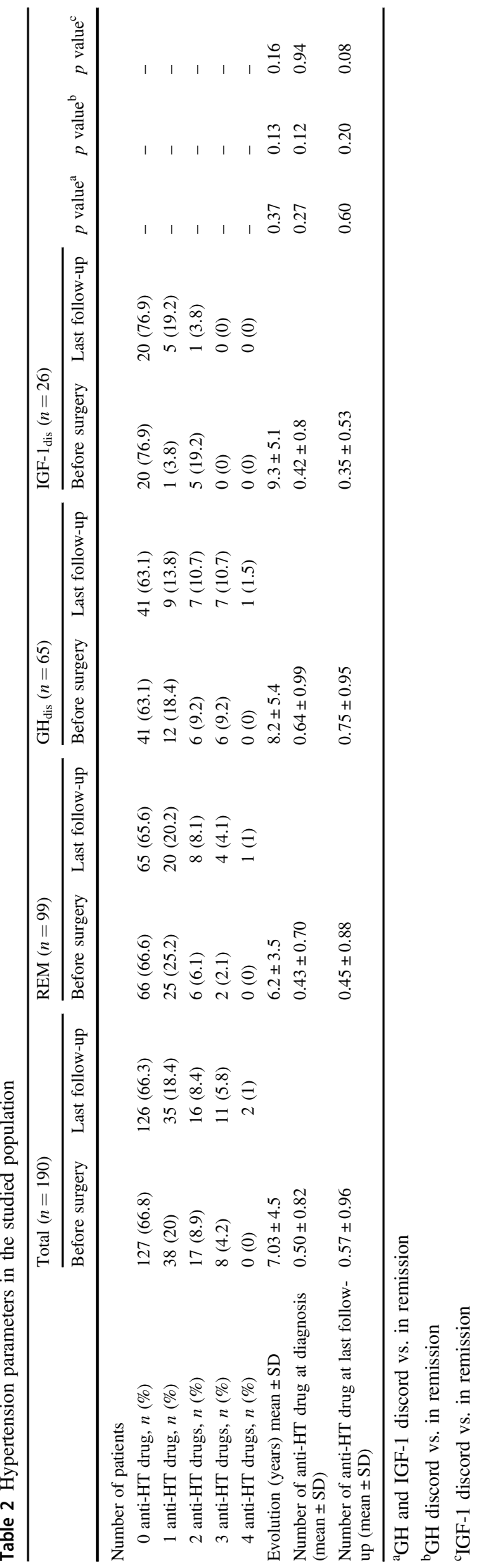




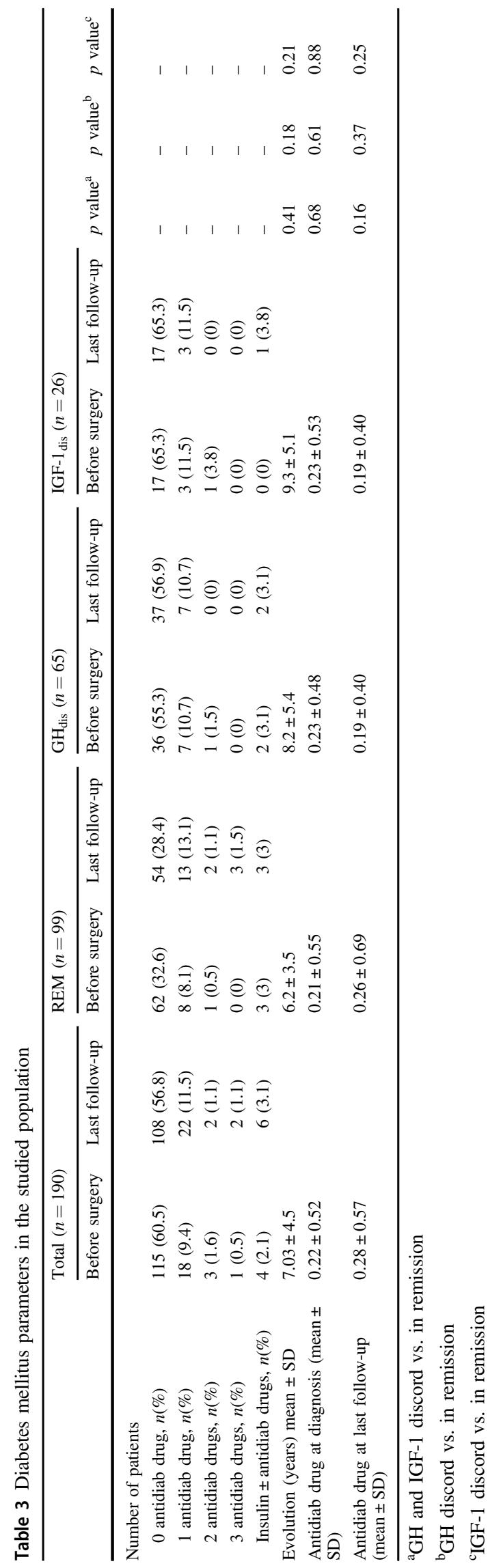

treated and naive of any medical therapies, given the fact that SSAs are known to increase the proportion of IGF-1 and GH discordant patients, depending on the study considered [21, 22]. Pegvisomant, a GH receptor antagonist, interferes with many conventional $\mathrm{GH}$ assays and may result in biased estimation of GH levels [23]. Finally, none of our patients underwent any modalities of radiotherapy. Together, these stringent criteria's of inclusion explain why we only identified 190 patients within a database of over 3000 patients. With a significant long-term follow-up on the one hand and with the exclusion of the main factors known to interfere or influence GH and/or IGF-1 value on the other, we found around $15 \%$ of real discordant (i.e., at least demonstrated on two samples during the follow-up) acromegalic patients in the LAS population. Roughly similar to the proportion observed by Machado and colleagues [18]. Moreover, we show that, when present, the discrepancy is usually mild, either for GH or IGF-1 and its real impact on the patient can consequently be questioned. Accordingly, our results do not show any adverse outcome for diabetes or HT in discordant acromegalic patients and further suggest that no matter what kind of biochemical parameter is discordant for the patient to predict and prevent the occurrence and aggravation of HT and/or diabetes. This latter point needs to be discussed in the light of the previous results observed in the LAS population, where data showed that in nondiabetic patients, glucose values (basal or at OGTT) did not correlate with GH levels, while a significant correlation with IGF-1 values (in absolute term or as \%ULN) was observed [17]. In this study however, a majority of patients had an IGF-1 $\geq 2$ ULN while in our group of IGF- $1_{\text {dis }}$ patients, the mean of IGF-1 was 1.3 ULN, which makes the comparison difficult to establish. Among our three groups (i.e., $\mathrm{REM}, \mathrm{GH}_{\mathrm{dis}}$, and $\mathrm{IGF}-1_{\mathrm{dis}}$ ), a trend for a higher BMI was observed at the last follow-up as compared with the mean value of BMI at the diagnosis, however without impacting the onset of metabolic comorbidities. This mild increase of BMI can result from two conditions to our opinion: firstly, BMI progressively increased with the age of the patients (mean follow-up of 6-9 years in our study) and, secondarily, biochemical control of acromegaly is a condition associated with an increase in fat mass and total body weight $[24,25]$. The repartition of the female population in our study deserves to be discussed as well. Overall, 55.5\%, $64.6 \%$, and $34.6 \%$ women were found in the REM, the $\mathrm{GH}_{\mathrm{dis}}$, and the IGF- $1_{\text {dis }}$ group, respectively, with a trend for a significant difference between the REM and the IGF- $1_{\text {dis }}$ group. Those results are pretty similar to the one observed in study by Alexoupoulou et al. [26], where the authors reported a lower proportion of female in the high IGF-1 group as compared with the $\mathrm{GH}_{\text {dis }}$ group (36\% vs. $72 \%$, respectively, $p<0.01$ ). A plausible assumption would be that circulating estrogen in women may cause a certain 
degree of GH resistance [27], which ultimately led to a biochemical pattern of "high" GH and "low" IGF-1.

As compared with the study published by Alexopoulou et al, in which the IGF-1 discordant group had higher fasting glucose (91 vs. $99 \mathrm{mg} / \mathrm{dl} ; p<0.05$ ), and glycated hemoglobin levels $(5.7$ vs. $6.1 \% ; p<0.01)$ [26], we did not observe a higher number of antidiabetic drugs in the IGF$1_{\text {dis }}$ group as compared with the REM and $\mathrm{GH}_{\text {dis }}$ groups. However, in this study the criteria used for discrepancy were different than the ones we used, with a cutoff for $\mathrm{GH}$ of $2 \mathrm{ng} / \mathrm{mL}$ to distinguish the controlled patients from the "high GH" group [26]. Another difference lies in the fact that we assessed the number of antidiabetic drugs for each patient and not the differences in terms of $\mathrm{HbAlc}$, such that mild variations of glycaemia and or HbA1c, did not automatically lead to an adjustment of the antidiabetic treatment. Matta et al. showed that discordant patients (defined in their study by patients with high IGF-1 and normal GH) had higher fasting blood glucose $(0.94 \mathrm{~g} / \mathrm{L}$ (interquartile range: $0.83-1.17)$ and systolic blood pressure $(130 \mathrm{mmHg}$ (120-140) compared with the control group $(0.84 \mathrm{~g} / \mathrm{l}$ $(0.80-0.92) ; p=0.017)$ and $120 \mathrm{mmHg}$ (interquartile range: $110-130 ; p=0.029$ ), respectively [28]. Although a trend for higher blood glucose values was observed, it did not result in a higher proportion of diabetic patients, which is line with our results. In our study, the proportion of prediabetic patients was roughly the same in the REM, $\mathrm{GH}_{\mathrm{dis}}$ and IGF- $1_{\text {dis }}$ group, however comparisons are hard to establish because of the small number of patients $(n=10)$. Therefore, several lines of evidence support the fact that biochemical discrepancy does not seem to significantly impact the occurrence of acromegalic metabolic comorbidities. Finally, in our study we did not include GH under OGTT to categorize the biochemical status of our patients. Clinicians can question the purpose of this decision. However, it relies on the fact that our population of patients had no visible evidence of pituitary residue on the MRI and because the validity of GH under OGTT as compared with random GH in the follow-up of acromegalic patients, in terms of metabolic outcomes, remains to be established properly [11]. In addition, our study shows that the prevalence of metabolic complications was the same in the $\mathrm{GH}_{\mathrm{dis}}$ and in the remission group, which naturally questioned the real benefit of GH under OGTT in this group of patients. Another line of evidence comes from the recent metanalysis conducted by Kanakis et al, where, by comparing random GH and GH under OGTT (=nadir GH), they found a roughly similar proportion of IGF-1 discordant patients (13.4\% and 8.3\%, respectively) [21]. More importantly, the proportion of GH discordant patients when considering random GH was similar to the one observed when using nadir GH (10.3\% and $13.6 \%$, respectively, NS) [21], whereas this specific subgroup of patients should be the one for who nadir GH should theoretically help to distinguish real discordance from active acromegaly. A total of 25 patients of our $\mathrm{GH}_{\text {dis }}$ population $(n=65)$ also had $\mathrm{GH}$ under OGTT. GH was suppressed in 12 patients and unsuppressed in the remaining 13 patients. Looking specifically at the metabolic outcomes of these two subgroups of patients (GH suppressed vs. GH unsuppressed), the prevalence of DM, HT or even the number of medications prescribed were comparable (data not shown). Overall, the positioning of nadir GH under HGPO in the follow-up of acrmegalic patients needs to be better delineated, and its results should be taken with caution given the numerous conditions that are known to influence its variability [29]. Because GH discrepancy can be the consequence of an analytical issue with the GH assay, it appears thus reasonable to assess GH level with another assay before considering GH under OGTT, especially if the increase of GH random remains mild.

Our study has obvious inherent limitations due to both its retrospective and multicentre nature. Firstly, we did not have the possibility to obtain similar kits for GH/IGF-1 measurement in the different centers. Variability of results obtained with different kits for GH has been underlined in many studies [30-32], however we assume in our study that each respective center used the same kit, and that each patient has been assessed with the same kit at diagnosis and LFU, a corner stone in the follow-up of patients with acromegaly. Moreover, patients enrolled in this study did not present any factors known to increase or decrease the value of IGF-1 like pregnancy, puberty, liver failure, kidney failure, estrogen treatment, or hypothyroidism. Another limitation relies in the fact that our inclusion criteria (patients who did not undergo medical therapy, second surgery or radiotherapy) probably led to a biased selection of only mild discordant patients. Therefore, our results have to be interpretated in this specific population of patients and have to be carefully extrapolated to acromegalic patients under medical therapies.

Our study focused on the number of administered drugs to the patient to treat HT and/or DM. Therefore, it gives an imperfect appreciation of the real metabolic status of the patient as far as he can still be diabetic without antidiabetic drugs if he is controlled with diet and exercise. However, patients were followed in expert centers where assessment and treatment of those two metabolic comorbidities are scrupulously screened and treated according to the guidelines. Moreover, our study shows that a trend for a significant decrease of mean $\mathrm{HbA1C}$ values occurred before $\mathrm{T} 1$ and LFU, which supports the idea that the number of antidiabetic drugs could reflect the degree of severity of DM in a given population. Finally, we postulated that no dramatic changes in the therapeutic regimen would signify that no significant changes occurred in the metabolic state of the patient over the period of follow-up. 
The problematic of discrepancy in daily life also questions the reliability of following one parameter (i.e., GH or IGF-1) in acromegaly. As discussed earlier, data originated from the LAS showed that glucose levels were correlated to the level of IGF-1 but not GH [17]. While GH has well known hyperglycemic properties [33], these results gave an interesting perspective for the interpretation of each of these parameters in the follow-up of acromegalic patients. Although it needs to be clearly demonstrated, it seems that GH reflect the secretory activity of the pituitary tumor (primitive or residue) while IGF-1 is mainly reflective of the disease activity. Based on this postulate, GH and IGF-1 appear to be indissociable parameters to manage the followup of patients with acromegaly. In that sense, a recent published meta-analysis, Bolfi et al. showed that in acromegalic patients with both normal IGF-1 and $\mathrm{GH}<2.5 \mathrm{ng} /$ $\mathrm{mL}$, observed deaths were not significantly different from the expected deaths in general population with a standardized mortality ratio (SMR) of 0.71 (CI: $0.41-1.22, I 262 \%$ ) [13]. On the contrary, uncontrolled GH or IGF-1 resulted in a significant increase of the SMR of 1.96 (CI: 1.25-3.05, I2: $78 \%$ ) as compared with the general population, according to this meta-analysis. Once medically treated, it remains unknown if targeting GH or IGF-1 instead of both parameters in patients with acromegaly could be a suitable strategy, however this question has been recently raised by the group of Dal et al. [34]. While somatostatin analogs have been associated either with a higher risk of GH discordance (i.e., IGF-1 normal with unsuppressed GH under OGTT) $[22,34,35]$ or a higher proportion of IGF-1 discordance [21], this study shows that increasing the dose of somatostatin analogs based on either GH or IGF-1, significantly increased the proportion of controlled patients after a follow-up of 12 months. No data are currently available regarding the impact of this strategy on the longterm outcome of acromegaly related comorbidities.

In summary, our study shows, with a long-term followup and a "real-life" approach, based on the intake of antidiabetic or antihypertensive drugs in closely monitored patients, that GH/IGF-1 discrepancy does not seem to expose the acromegalic patient to a higher risk of metabolic comorbidities. These results appear all the more relevant as discrepancy arose progressively as an issue over the past years, secondary to the systematic assessment of GH biomarkers (i.e., nadir GH and/or fasting GH) and IGF-1 with even more stringent criteria, while it was not necessarily the case in the past [36]. Moreover, in the same period, data from several acromegaly national registries showed a significant improvement of the management of the disease with a SMR similar than the one of the general population $[10,37]$. Lastly, our study shows that biochemical discrepancy, when occurring, is mild in a majority of cases and should not warrant specific care for the patient, apart from the one recommended by the current guidelines in patients with concordant remission criteria.

Acknowledgements This work was funded by an unrestricted grant from IPSEN to Albert Beckers.

\section{Compliance with ethical standards}

Conflict of interest The authors declare that they have no conflict of interest.

Ethical approval All procedures performed in studies involving human participants were in accordance with the ethical standards of the institutional and/or national research committee and with the 1964 Helsinki declaration and its later amendments or comparable ethical standards.

Informed consent Informed consent was obtained from all individual participants included in the study.

Publisher's note Springer Nature remains neutral with regard to jurisdictional claims in published maps and institutional affiliations.

\section{References}

1. A. Colao, L.F.S. Grasso, A. Giustina, S. Melmed, P. Chanson, A.M. Pereira, R. Pivonello, Acromegaly. Nat. Rev. Dis. Prim. 5, 20 (2019)

2. M.R. Gadelha, L. Kasuki, D.S.T. Lim, M. Fleseriu, Systemic complications of acromegaly and the impact of the current treatment landscape: an update. Endocr. Rev. 40, 268 (2019)

3. A. Giustina, A. Barkan, A. Beckers, N. Biermasz, B.M.K. Biller, C. Boguszewski, M. Bolanowski, V. Bonert, M.D. Bronstein, F.F. Casanueva, D. Clemmons, A. Colao, D. Ferone, M. Fleseriu, S. Frara, M.R. Gadelha, E. Ghigo, M. Gurnell, A.P. Heaney, K. Ho, A. Ioachimescu, L. Katznelson, F. Kelestimur, J. Kopchick, M. Krsek, S. Lamberts, M. Losa, A. Luger, P. Maffei, M. Marazuela, G. Mazziotti, M. Mercado, P. Mortini, S. Neggers, A.M. Pereira, S. Petersenn, M. Puig-Domingo, R. Salvatori, I. Shimon, C. Strasburger, S. Tsagarakis, A.J. van der Lely, J. Wass, M.C. Zatelli, S. Melmed, A consensus on the diagnosis and treatment of acromegaly comorbidities: an update. J. Clin. Endocrinol. Metab. 105, e937 (2020)

4. P. Kamenický, G. Mazziotti, M. Lombès, A. Giustina, P. Chanson, Growth hormone, insulin-like growth Factor-1, and the kidney: pathophysiological and clinical implications. Endocr. Rev. 35, 234 (2014)

5. S. Puglisi, M. Terzolo, Hypertension and acromegaly. Endocrinol. Metab. Clin. N. Am. 48, 779 (2019)

6. S. Frara, F. Maffezzoni, G. Mazziotti, A. Giustina, Current and emerging aspects of diabetes mellitus in acromegaly. Trends Endocrinol. Metab. 27, 470 (2016)

7. D. Niculescu, M. Purice, M. Coculescu, Insulin-like growth factor-I correlates more closely than growth hormone with insulin resistance and glucose intolerance in patients with acromegaly. Pituitary 16, 168 (2013)

8. O.M. Dekkers, N.R. Biermasz, A.M. Pereira, J.A. Romijn, J.P. Vandenbroucke, Mortality in acromegaly: a metaanalysis. J. Clin. Endocrinol. Metab. 93, 61 (2008)

9. L. Katznelson, E.R. Laws, S. Melmed, M.E. Molitch, M.H. Murad, A. Utz, J.A.H. Wass, Acromegaly: an endocrine society clinical practice guideline. J. Clin. Endocrinol. Metab. 99(11), 3933-3951 (2014) 
10. L. Maione, T. Brue, A. Beckers, B. Delemer, P. Petrossians, F. Borson-Chazot, O. Chabre, P. Franłois, J. Bertherat, C. CortetRudelli, P. Chanson, Changes in the management and comorbidities of acromegaly over three decades: The French acromegaly registry. Eur. J. Endocrinol. 176(5), 645-655 (2017)

11. S. Melmed, M.D. Bronstein, P. Chanson, A. Klibanski, F.F. Casanueva, J.A.H. Wass, C.J. Strasburger, A. Luger, D.R. Clemmons, A. Giustina, A consensus statement on acromegaly therapeutic outcomes. Nat. Rev. Endocrinol. 14, 552 (2018)

12. C.R. Ku, E.Y. Choe, J.W. Hong, E.H. Kim, S.H. Park, S.H. Kim, E.J. Lee, No differences in metabolic outcomes between nadir GH 0.4 and $1.0 \mathrm{ng} / \mathrm{mL}$ during OGTT in surgically cured acromegalic patients (observational study). Medicine 95, e3808 (2016)

13. F. Bolfi, A.F. Neves, C.L. Boguszewski, V.S. Nunes-Nogueira, Mortality in acromegaly decreased in the last decade: a systematic review and meta-analysis. Eur. J. Endocrinol. 179, 59 (2018)

14. A. Colao, L.F.S. Grasso, M. Di Cera, P. Thompson-Leduc, W.Y. Cheng, H.C. Cheung, M.S. Duh, M.P. Neary, A.M. Pedroncelli, R. Maamari, R. Pivonello, Association between biochemical control and comorbidities in patients with acromegaly: an Italian longitudinal retrospective chart review study. J. Endocrinol. Investig. 43(4), 529-538 (2020)

15. J.A. Brzana, C.G. Yedinak, J.B. Delashaw, H.S. Gultelkin, D. Cook, M. Fleseriu, Discordant growth hormone and IGF-1 levels post pituitary surgery in patients with acromegaly na<ve to medical therapy and radiation: what to follow, GH or IGF-1 values? Pituitary 15(4), 562-570 (2012)

16. P. Petrossians, M.A. Tichomirowa, A. Stevenaert, D. Martin, A.F. Daly, A. Beckers, The Liege Acromegaly Survey (LAS): a new software tool for the study of acromegaly. Ann. Endocrinol. 73, 190 (2012)

17. P. Petrossians, A.F. Daly, E. Natchev, L. Maione, K. Blijdorp, M. Sahnoun-Fathallah, R. Auriemma, A.M. Diallo, A.-L. Hulting, D. Ferone, V. Hana, S. Filipponi, C. Sievers, C. Nogueira, C. Fajardo-Montañana, D. Carvalho, V. Hana, G.K. Stalla, M.-L. Jaffrain-Réa, B. Delemer, A. Colao, T. Brue, S.J.C.M.M. Neggers, S. Zacharieva, P. Chanson, A. Beckers, Acromegaly at diagnosis in 3173 patients from the Liège Acromegaly Survey (LAS) Database. Endocr. Relat. Cancer 24, 505 (2017)

18. E.O. Machado, G.F. Taboada, L.V. Neto, F.R. van Haute, L.L. Corrêa, G.A. Balarini, Y. Shrank, M. Goulart, M.R. Gadelha, Prevalence of discordant GH and IGF-I levels in acromegalics at diagnosis, after surgical treatment and during treatment with octreotide LAR ${ }^{\circledR}$. Growth Horm. IGF Res. 18, 389 (2008)

19. F.Gatto, C. Campana, F. Cocchiara, G. Corica, M. Albertelli, M. Boschetti, G. Zona, D. Criminelli, M. Giusti, D. Ferone, Current perspectives on the impact of clinical disease and biochemical control on comorbidities and quality of life in acromegaly. Rev. Endocr. Metab. Disord. 20(3), 365-381 (2019)

20. I.M. Holdaway, R.C. Rajasoorya, G.D. Gamble, Factors influencing mortality in acromegaly. J. Clin. Endocrinol. Metab. 89, 667 (2004)

21. G.A. Kanakis, A. Chrisoulidou, A. Bargiota, Z.A. Efstathiadou, L. Papanastasiou, A. Theodoropoulou, S.K.Tigas, D.A. Vassiliadi, S. Tsagarakis, M. Alevizaki, The ongoing challenge of discrepant growth hormone and insulin-like growth factor I results in the evaluation of treated acromegalic patients: a systematic review and meta-analysis. Clin. Endocrinol. 85(5), 681-688 (2016)

22. J. D. Carmichael, V.S. Bonert, J.M. Mirocha, S. Melmed, The utility of oral glucose tolerance testing for diagnosis and assessment of treatment outcomes in 166 patients with acromegaly. J. Clin. Endocrinol. Metab. 94(2), 523-527 (2009)
23. A.N. Paisley, K. Hayden, A. Ellis, J. Anderson, G. Wieringa, P.J. Trainer, Pegvisomant interference in GH assays results in underestimation of GH levels. Eur. J. Endocrinol. 156, 315 (2007)

24. T.J. Reid, Z. Jin, W. Shen, C.M. Reyes-Vidal, J.C. Fernandez, J. N. Bruce, J. Kostadinov, K.D. Post, P.U. Freda, IGF-1 levels across the spectrum of normal to elevated in acromegaly: relationship to insulin sensitivity, markers of cardiovascular risk and body composition. Pituitary 18, 808 (2015)

25. C. Reyes-Vidal, J.C. Fernandez, J.N. Bruce, C. Crisman, I.M. Conwell, J. Kostadinov, E.B. Geer, K.D. Post, P.U. Freda, Prospective study of surgical treatment of acromegaly: effects on ghrelin, weight, adiposity, and markers of CV risk. J. Clin. Endocrinol. Metab. 99, 4124 (2014)

26. O. Alexopoulou, M. Bex, R. Abs, G. T'Sjoen, B. Velkeniers, D. Maiter, Divergence between growth hormone and insulin-like growth factor-I concentrations in the follow-up of acromegaly. J. Clin. Endocrinol. Metab. 93, 1324 (2008)

27. K.-C. Leung, G. Johannsson, G.M. Leong, K.K.Y. Ho, Estrogen regulation of growth hormone action. Endocr. Rev. 25, 693 (2004)

28. M. Matta, V. Bongard, S. Grunenwald, J.-C. Maiza, A. Bennet, P. Caron, Clinical and metabolic characteristics of acromegalic patients with high IGF1/normal GH levels during somatostatin analog treatment. Eur. J. Endocrinol. 164, 885 (2011)

29. M. Hage, P. Kamenicky, P. Chanson, Growth hormone response to oral glucose load: from normal to pathological conditions. Neuroendocrinology 108, 244 (2019)

30. A. Pokrajac, G. Wark, A.R. Ellis, J. Wear, G.E. Wieringa, P.J. Trainer, Variation in GH and IGF-I assays limits the applicability of international consensus criteria to local practice. Clin. Endocrinol. 67, 65 (2007)

31. A.M. Arafat, M. M"hlig, M.O. Weickert, F.H. Perschel, J. Purschwitz, J. Spranger, C.J. Strasburger, C. Sch"fl, A.F.H. Pfeiffer, Growth hormone response during oral glucose tolerance test: the impact of assay method on the estimation of reference values in patients with acromegaly and in healthy controls, and the role of gender, age, and body mass index. J. Clin. Endocrinol. Metab. 93(4), 1254-1262 (2008)

32. M. Bidlingmaier, P.U. Freda, Measurement of human growth hormone by immunoassays: Current status, unsolved problems and clinical consequences. Growth Horm. IGF Res. 20, 19 (2010)

33. J.O.L. Jørgensen, M. Krag, N. Jessen, H. Nørrelund, E.T. Vestergaard, N. Møller, J.S. Christiansen, Growth Hormone and Glucose Homeostasis. Horm. Res. Paediatr. 62, 51 (2004)

34. J. Dal, M. Klose, A. Heck, M. Andersen, C. Kistorp, E.H. Nielsen, J. Bollerslev, U. Feldt-Rasmussen, J.O.L. Jørgensen, Targeting either GH or IGF-I during somatostatin analogue treatment in patients with acromegaly: a randomized multicentre study. Eur. J. Endocrinol. 178, 65 (2018)

35. M. Christiansen Arlien-Søborg, C. Trolle, E. Alvarson, A. Bæk, J. Dal, J.O.L. Jørgensen, Biochemical assessment of disease control in acromegaly: reappraisal of the glucose suppression test in somatostatin analogue (SA) treated patients. Endocrine 56, 589 (2017)

36. L. Katznelson, J.L.D. Atkinson, D.M. Cook, S.Z. Ezzat, A.H. Hamrahian, K.K. Miller, American Association of Clinical Endocrinologists, American Association of Clinical Endocrinologists medical guidelines for clinical practice for the diagnosis and treatment of acromegaly-2011 update. Endocr. Pract. 17(Supplement 4), 1-44 (2011)

37. L. Maione, P. Chanson, National acromegaly registries. Best Pract. Res. Clin. Endocrinol. Metab. 33, 101264 (2019) 